\title{
Notas sobre joyería tradicional en la provincia de Madrid
}

\section{INTRODUCCIÓN}

Es ya un lugar común comenzar los trabajos de cultura tradicional en la provincia de Madrid refiriéndose al vacío de publicaciones existente sobre el tema; acaso la supuesta falta de una personalidad definida de la región es lo que hizo que ninguno de los estudios clásicos sobre etnografía reparase en estos casi doscientos pueblos que componen la actual Comunidad. Uno de los apartados peor parados en este aspecto ha sido el de la indumentaria tradicional, y a esta carencia hay que unir la falta de referencias disponibles sobre el asunto en las provincias de nuestro entorno ${ }^{1}$. Dibujantes, escritores y grabadores rara vez se fijaron en el atavío de los campesinos de Guadalajara, Cuenca o el sector oriental de la provincia de Toledo, áreas con las cuales comparte rasgos y usos el territorio madrileño. Bien es verdad que, enclavada nuestra provincia en la que Luis de Hoyos, en la división que propuso de las áreas de la ornamentación en la Península Ibérica ${ }^{2}$, denominó zona Central o Ibérica, y que presenta un carácter pobre y más impersonal, poco pintoresquismo podían ofrecer nuestras modestas paletas y serranas al lado del arcaísmo y lujo de segovianas y abulenses, por poner ejemplos bien cercanos y representativos. Así pues, el estudio del vestido y, como parte integrante de él, de la joyería popular, que es lo que nos ocupa en este artículo, debe realizarse acudiendo fundamentalmente a la documentación contenida en los archivos de protocolos de la época (con sus cartas dotales, capitales de bienes, mandas testamentarias e inventarios) y a los datos obtenidos en el trabajo de campo, sea en el recuerdo de los informantes o en las piezas-testigo conservadas; sin despreciar lo poco que en grabados y fotografías antiguas aparece, que, en algunos casos, suplen su escasez por una calidad extraordinaria.

1 Excepto, quizá, de Ávila y Segovia, de las que se encuentra abundante material gráfico, aunque carentes todavía de un estudio en profundidad.

2 Luis de HOYOS SÁINZ y Nieves de HOYOS SANCHO, "Zonas de la ornamentación en los trajes populares de España", RDTP, IX (1953), pp. 126-129. 
Los protocolos consultados abarcan, grosso modo, de 1750 a $1850{ }^{3}$. Después de esta fecha son escasísimos los que inventarían bienes, y si lo hacen, suelen ser de casa tan rica, que lo allí reflejado coincide íntegramente con la moda urbana occidental. La mayoría proceden del Archivo Histórico de Protocolos de Madrid. Consérvanse allí documentos de los antiguos distritos de Aranjuez, Chinchón, Getafe, Navalcarnero y San Lorenzo del Escorial. El Archivo de Alcalá de Henares fue parcialmente destruido en la última guerra y por esta razón no existen protocolos anteriores a 1830, cuando ya los inventarios empiezan a escasear, a la vez que las prendas apuntadas van "urbanizándose". Los documentos del área Norte de la provincia (Archivo de Torrelaguna) son extremadamente parcos en lo que a inventarios se refiere; tan sólo en las villas de cierta importancia se nombran joyas, dándose el caso de que en ninguno de los lugares de la Sierra Norte -que conservaron la indumentaria tradicional hasta ayer mismo- parece que existiera la costumbre de detallar las dotes o las particiones. Hay que rastrear en los testamentos que, rebosantes de venerables monteras femeninas y prendas de estezado, apenas mencionan siquiera de refilón elementos de joyería o adorno personal. San Martín de Valdeiglesias posee un archivo de dificultoso acceso, esperemos que transitoriamente ${ }^{4}$, pero con lo poco que hemos visto creemos que posteriores consultas podrían proporcionar gratas sorpresas. Finalmente, el Archivo de Colmenar Viejo se encuentra hasta la fecha en paradero desconocido, por lo que, lamentablemente, su distrito está ausente de nuestro trabajo en lo referente a documentación escrita. De un total de 1227 documentos consultados aparecen joyas en un tercio, aproximadamente. Las encuestas de campo fueron realizadas entre los años 1986 y 1996 por José Manuel Fraile Gil y el autor ${ }^{5}$.

3 En el presente estudio hemos dejado fuera la ciudad de Madrid, considerando que las especiales características que reviste exigen que se trate separadamente, no obstante la estrecha relación que existió siempre entre la capital y los pueblos de su alrededor en todos sus aspectos.

4 No obstante, quiero agradecer tanto al personal de este archivo como al de los otros restantes por su desinteresada colaboración, así como a mi amiga Begoña Martín por su infinita paciencia en la transcripción de estas líneas.

5 Fueron nuestros informantes en la Sierra: Margarita Coll (Lozoya), Victoriano Sanz Araújo (La Acebeda), Mónica García Suárez (La Puebla), Elena Serrano del Pozo (Horcajo), Milagros y Felisa de Frutos (Montejo), Mercedes Serrano San José (Valdemanco), Petra González Martín (Guadalix), Juana Tato Calleja (Colmenar Viejo), Valero González del Valle (El Boalo) y Esperanza Martín (Robledondo). En otras zonas: Andrea Gómez Torres (Villar del Olmo), Paula Torres Pérez (Chinchón), Carmen Arias Horcajada (Colmenar de Oreja), Isidra Camacho Horcajo (Estremera), Eduarda Pérez (Villamanta), Pilar García (Villabilla), Isabel Ventura Ceredo, Elena Huelves y 
El aspecto más característico de la joyería en la provincia de Madrid acaso sea su discreción. El aderezo de las mujeres del pueblo se reducía casi siempre a los inexcusables pendientes y a alguna vuelta de cuentas corrientes rodeando la garganta. Así representaron los pocos dibujantes que lo hicieron tanto a la paleta como a la serrana, arquetipos que se perfilan hacia la segunda mitad del siglo XIX, que es la época de la que proceden los escasos grabados que conocemos. No obstante, los inventarios nos hablan de una riqueza y variedad algo más amplias y, aunque a veces eran sólo las casas de cierto nivel económico las que podían permitirse pagar al escribano, sabemos por testimonios orales sobre la costumbre de colgarse al cuello las labradoras relicarios de cerco y vidriera, o de la abundancia de botones plateados que guarnecían chalecos y calzones, tanto en la Sierra como en el Llano.

Agruparemos las joyas bajo epígrafes genéricos según su denominación en los inventarios, forma y uso, intentando que estos tres aspectos se ajusten del modo más coherente posible. Cada apartado recoge ejemplos tomados de los protocolos, procurando que queden representadas todas las variantes que aparecen, así como los pueblos en que lo hacen; y en cada parte incluiremos las pocas referencias literarias y las muchas orales que nos han llegado.

\section{EL ADEREZO}

Por aderezo se entiende el conjunto de joyas que luce la mujer con el traje festivo o de ceremonia, y en el que a las piezas imprescindibles - pendientes y cruz u otra pieza del cuello- suelen añadirse pulseras (en el caso de las economías más prósperas), anillos, sortijas o elementos para el peinado. Responden a una cierta universalización de la moda y su origen está en los suntuosos conjuntos que portaban las damas de las cortes europeas del xviII, que tuvieron una gran aceptación, en imitaciones de inferior calidad y fueron muy apreciados por las mujeres del pueblo. Tanto es así, que en algunas zonas pasaron a formar parte del arquetipo de traje regional que pervivió durante todo el siglo XIX: es el caso del Levante peninsular o de ciertos valles pirenaicos, navarros y aragoneses. También tenemos referencias de su uso en el oeste del país, bien es verdad que con derivaciones de carácter más tradicional.

Tomasa Navarro (Valdaracete), Victoria González del Saz (Fuentidueña), María Alfonso Sánchez (Cadalso) y Sandalio Ventura (Fresnedillas). A todos ellos nuestro más profundo agradecimiento. 
En los protocolos de Madrid encontramos estos aderezos en un espacio de tiempo bastante amplio (de 1764 a 1858) aunque empiezan a escasear en los inventarios hacia los años veinte de la pasada centuria. En general, parecen responder más al tipo aragonés-levantino, en el que la pieza central pende de una cinta o galón de seda, frente a los de la zona oeste, donde suele ser parte de un bilo de granos de oro. Prácticamente todos están realizados en plata, donde se engastan las populares piedras de Francia (estrás). Sobre el uso de piedras falsas en la joyería española, tenemos dos documentos bastante ilustrativos. Uno es del siglo XVII y el otro de mediados del XIX. Veamos en primer lugar lo que nos dice Madame d'Aulnoy de las damas madrileñas de la época:

[...] pero todo les satisface, agujas, horquillas, algunas cintas, y sobre todo, algunas pedrerías falsas las encantan; ellas, que poseen tantas finas y que son tan bellas, no dejan de llevar otras malas, que no son más que pedazos de vidrio labrados toscamente, enteramente semejantes a los que los vendedores ambulantes venden a nuestras provincianas. [...] Las más distinguidas damas van cargadas de esos vidrios $[\ldots]^{6}$

Casi doscientos años después, otro viajero francés, el barón Charles Davillier, nos dice después de hablar del traje de las charras salmantinas:

Digamos un detalle curioso sobre las esmeraldas: estas piedras han desempeñado siempre un gran papel en las joyas populares de España, y parece ser que la moda no ha de acabar tan pronto. Es verdad que la mayoría de las veces se trata de esmeraldas de la clase más ordinaria, lo cual las pone al alcance de las personas más modestas, y que muchas veces son reemplazadas por imitaciones de cristal $^{7}$

A la luz de lo reflejado en los inventarios, anotemos que las piedras de imitación gozaron de una gran popularidad en la provincia, al menos hasta la década de los treinta del siglo XIX. En las familias pudientes apuntan ricos aderezos de oro y diamantes: "un aderezo de chispas de diamante engarzado o embutido en oro q.e se compone de Cruz Arracadas y anillo $=1380$ rs." (Valdemorillo, 1772); "un Aderezo de Diamantes $=5000$ rs." (Pinto, 1789); "un aderezo de diamantes con su cruz, pendientes y sortija engarzado en oro = 2000 rs." (Chinchón, 1805); "un Aderezo de cruz y pendientes de Oro y Diamantes = 700 rs." (San Martín de Valdeiglesias, 1820).

6 Marie Catherine D'Aulnoy, Relación del viaje de España (1679-1681) (ed. de G. Mercadal) (Madrid: Akal, 1986), p. 346.

7 Charles DaviluIER, Viaje por España (1862) (trad. de Isabel Gil de Ramales) (Madrid: Ed. Giner, 1991), IV, p. 114. 
Remedo de estos lujosos conjuntos, los de plata y piedras de Francia aparecen formando parte de la dote de mujeres de las más variadas economías. Así, desde los más simples formados por los elementos mínimos, normalmente cruz y pendientes: "Aderezo Cruz y pendientes $=20$ rs." (Valdemorillo, 1799), "un aderezo de Cruz y Pendientes de Piedras $=60$ rs." (Móstoles, 1798), "un Aderezo de Cruz y Pend.tes $=20$ rs." (Bustarviejo, 1806); a los que incorporan todos los elementos del vestido que pueden incluirse en la joyería. María Millán, de Majadahonda, llevó en su dote, en marzo de 1791, un aderezo que podemos considerar modélico por cuanto recoge los elementos más característicos del vestir popular de su época: "un Aderezo con Arracadas de Piedras de Franz. ${ }^{a}$ Cruz, Medalla, Evillas, y catorce Botones de Plata $=235$ rs." (Majadahonda, 1791). Otros ejemplos de aderezos de piedras:

"dos Aderezos el uno berde, y el otro con piedras blancas $=130$ rs." (Estremera de Tajo, 1769); “un Aderezo de piedras de Francia = 60 rs." (El Álamo, 1789); "un Aderezo de Plata piedra de Francia $=444$ rs." (Pinto, 1790); "un aderezo de Pied. de Fran.cia con Pulseras y pend.tes engarce de Plata $=100$ rs." (Carabaña, 1792); "un Aderezo de Piedras de Francia = 40rs." (Cubas de la Sagra, 1798); "un Aderezo de piedras de francia engarzado en plata $=60 \mathrm{rs} . "$ (Brunete, 1799); "dos aderezos de plata con piedras $=60 \mathrm{rs}$." (Navalcarnero, 1800); "un aderezo de piedras de francia blancas $=80$ rs." (Colmenar de Oreja, 1800); "un aderezo con sus pendientes correspondientes de piedras de francia engastado en plata $=48 \mathrm{rs}$." (Pozuelo de Alarcón, 1803); "...un Aderezo de Piedras de Francia engarzado en Plata.... (Chinchón, 1805); "un aderezo de piedras de francia $=70$ rs." (Torrelaguna, 1808); "un aderezo de plata completo de piedras de Francia $=80$ rs." (Villarejo de Salvanés, 1819); "un Aderezo de piedras de francia $=30$ rs." (San Martín de Valdeiglesias, 1820); "un aderezo de garganta entero con piedras blancas $=8$ rs., un par de pendientes compañeros $=30$ rs." (Miraflores de la Sierra, 1858).

Queremos dar una idea de la cantidad y extensión geográfica de estos conjuntos en la provincia. Como dijimos, el término aderezo ha pasado a designar genéricamente al grupo de joyas que se llevan con el traje festivo, respondan o no a la forma dieciochesca, y así lo hemos oído decir en Miraflores de la Sierra. En otros pueblos, como Robledondo, llaman las alhajas al conjunto formado por pendientes, gargantillas y relicarios.

Describamos ahora separadamente las partes componentes de dicho conjunto, sirviéndonos del completísimo equipo que llevó en su dote Isabel de la Calle en Alcorcón en 1765, expresivo paradigma de todos los elementos que nos iremos encontrando:

una Cruz de plata para el Cuello con su Cavezera; un par de Pendientes de Aljofar con sus Arillos de plata; Dos pares de Botones de plata con sus piedras para los puños; Una Sortija de plata con su Piedra enmedio; Once Medallas de plata 
chiquititas, y medianas, en que se Incluie una Cara de Dios, y un relicario; Cinco Cruzes todo de plata; Un Rosario Estrellado engarzado con Cordon de seda de color de oro con su borla de lo mismo, y una Medalla grande de Nieba de plata $=192$ rs. (Alcorcón, 1765).

PENDIENTES, ARRACADAS, ARILlOS, BROQUELILLOS

Los pendientes son, quizá, el elemento más característico de la joyería popular. Prácticamente no había mujer que no los gastase a diario, fuese cual fuese su nivel económico y, aunque sabemos que en algunas épocas fueron usados también por los hombres, puede decirse que - al menos en todo el ámbito mediterráneo- son un adorno propio del sexo femenino, llegando a caracterizarlo. Nos contaban en Estremera de Tajo cómo era la comadrona la encargada de hacer los agujeros en las orejas de las niñas, minutos después de venir al mundo. En el recién abierto orificio se colocaba un hilo que siempre había de ser de seda y durante un número impar de días - de tres a nueve- la madre humedecía los dedos en su propia saliva y con ellos desplazaba el hilo con objeto de que al cicatrizar la herida no quedase pegado a la carne. Para que fuera efectivo este proceso, la operación debía verificarse en ayunas ${ }^{8}$. Pasado este tiempo, se le colocaban a la niña unos abridores, por lo general de oro, aunque en Estremera nos indicaron que eran siempre de plata; breves arillos, que aparecen en algún inventario: "unos abridores de oro $=5 \mathrm{rs}$." (Valdaracete, 1872), y se llevaban durante un año aproximadamente, transcurrido el cual la niña pasaba a lucir unos pendientes que, a decir de nuestras informantes, en nada diferían de los de las adultas (Fig. 1). En otros lugares (La Acebeda) las niñas permanecían con

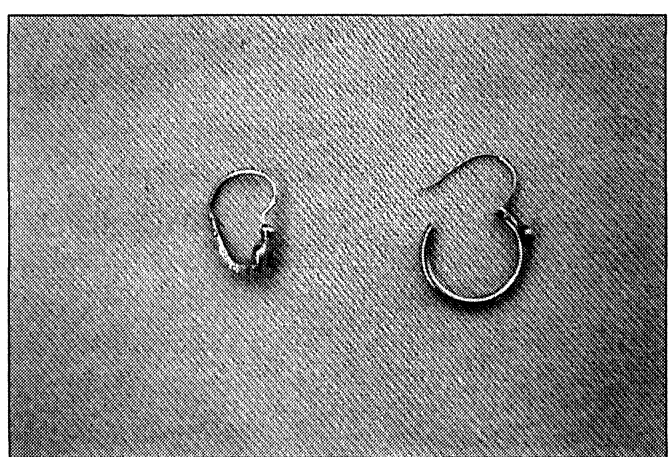

FIG. 1.-Abridores. Chinchón. los lóbulos sin abrir hasta los dos años, edad a la que se les colocaba directamente los abridores.

En la documentación de archivo los pendientes más abundantes son los de piedra francesa, engastada por lo común en plata, y en relación con los aderezos antes reseñados, formando a veces parte de ellos:

8 Ascensión Martín Bozada, de Robregordo, nos contaba cómo perdió los flecos un pañuelo de seda de su madre por lo solicitadas que eran estas hebras para ese fin. 
"un par de pendientes de plata con piedras $=20$ rs." (El Álamo, 1790); "unos pendientes de piedras en plata $=40$ rs." (Pinto, 1790); "unos Pendientes de Piedras de Francia $=33$ rs." (Estremera de Tajo, 1798); "unos Pendientes de Piedras falsas = 90 rs." (Navalcarnero, 1802); "un par de pendientes de piedras de francia $=30$ rs." (Fuenlabrada, 1802); «un par de pendientes de piedras falsas engastados en plata $=10$ rs." (Pozuelo de Alarcón, 1803); "unos Pendientes de Piedras de Francia $=30$ rs." (Chinchón, 1808); "unos pendientes de piedras $=40$ rs." (Torrelaguna, 1810); "un Par de Pendientes de metal con Piedras = 4rs." (Villamanta, 1810); "un Par de Pendientes de piedras $=25$ rs." (Humanes de Madrid, 1811), "un par de pend.tes de Plata con piedras de Francia = 60rs." (Villarejo de Salvanés, 1818); "un Par de Pendientes de Plata con piedras = 10rs." (San Martín de Valdeiglesias, 1820); "unos Pend.tes con piedras" (Corpa, 1837); "unos pendientes de acero con piedras $=30$ rs." (Torrejón de Velasco, 1837); "unos pendientes de piedras de francia $=24 \mathrm{rs} . n$ (Campo Real, 1840).

En algunos inventarios, y también como parte integrante de los aderezos, encontramos las arracadas. En otras provincias dan este nombre a los pendientes de las casadas o aluden a una forma característica?. Por solo los datos contenidos en estos protocolos no podríamos concluir en qué consistía la diferencia con los pendientes; coinciden básicamente en los materiales y uso, por lo que las reseñamos aquí junto a ellos, siquiera para comparar la composición que presentan:

"unas Arracadas de piedras en plata $=30$ rs." (El Álamo, 1791); "unas Arracadas de piedras de francia $=20$ rs." (Brunete, 1801); "unas arracadas de piedras de Francia $=30$ rs." (Navalcarnero, 1802); "un par de arrecadas de piedras de francia $=60$ rs." (Carabanchel de Arriba, 1803); "unas Arracadas con los gajos de nacar, y lo demas de piedras de francia $=60$ rs." (Villamantilla, 1810); "dos Arracadas de Piedras de francia $=20$ rs." (Arganda del Rey, 1813); "unas arracadas de plata con piedras de francia $=30$ rs.. (Cubas de la Sagra, 1816).

Los colores de estas piedras son nombrados en muy pocas ocasiones; suponemos que serían blancas en su mayoría, remedando los diamantes de los lujosos aderezos a los que imitaban: "unos pendientes con Piedras verdes $=30 \mathrm{rs}$, otros con Piedras blancas $=25 \mathrm{rs} . "$ (Cubas de la Sagra, 1796); "un Par de Pendientes de Piedras blancas engarzado en Plata" (Villamanta, 1809); "unos pendientes largos con piedras azules = 12rs." (Campo Real, 1838); "unos pendientes de piedras blancas $=30$ rs." (Miraflores de la Sierra, 1858).

Tampoco se prodigan las descripciones de sus formas. Vagas notas sobre su longitud o los cuerpos que los conforman. Es de suponer que en la época que nos ocupa guardaran muchos de ellos el clásico esque-

9 Véase Luis ARGÜELLES, Indumentaria popular en Asturias (Gijón: GH Ed., 1986), pp. 67-68. 


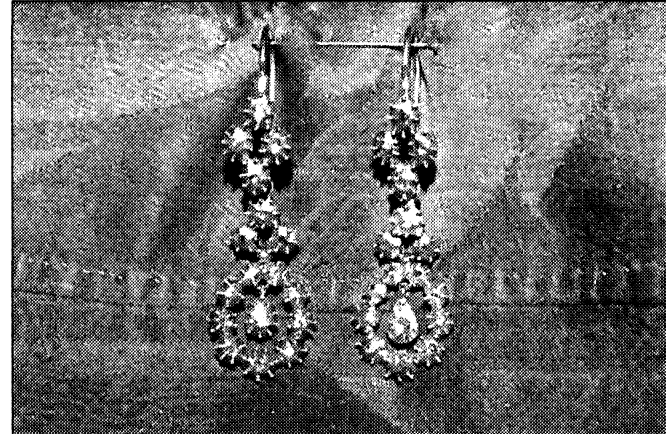

FIG. 2.-Pendientes de piedras. Valdaracete. $4,5 \mathrm{~cm}$

ma de tres órdenes, por analogía con los aparecidos en otras zonas ${ }^{10}$. Desgraciadamente, y exceptuando alguna pieza que se aparta bastante de lo común (Fig. 2), no hemos encontrado por el momento en nuestra provincia ningún ejemplar de estos populares pendientes:

*...unos pendientes de piedras de tres Gaxos..." (El Álamo,1787); "unos pendientes de tres Almendras de engarce de Piedras de Francia $=$ 50rs." (Cubas de la Sagra, 1794); "un par de pendientes de tres gajos pedreados $=50 \mathrm{rs."} \mathrm{(El} \mathrm{Álamo,} \mathrm{1795);} \mathrm{"unos} \mathrm{pendientes} \mathrm{de} \mathrm{tres} \mathrm{gajos} \mathrm{de}$ piedras de francia $=40$ rs." (Chinchón,1805); "unos pendientes de tres gajos de almendrilla" (San Lorenzo del Escorial, 1807); "unos pendientes de Plata de tres gajos = 40rs." (Chinchón, 1809); uunos pendientes de Gajos" (Santorcaz, 1834); "un par de pendientes largos, y otros de gajos $=40 \mathrm{rs} . "$ (Corpa, 1837); "unos pendientes largos de piedras $=160$ rs." (San Lorenzo del Escorial, 1837).

Y poco más. Por gajos se entiende unas porciones o extremos, posiblemente en forma de almendra, análogos a los valencianos pendientes de a tres $^{11}$; pero gajas llaman también en Zamora a los palillos en forma de vaina que penden de cierto tipo de arracadas ${ }^{12}$, y esto quizá esté en relación con otra forma de pendientes que siguen en abundancia a los antes mencionados, los pendientes de aljófar: "unos pendientes de Aljofar = 20rs." (El Álamo, 1789); "unos pendientes de aljofar =40rs" (Pinto, 1790); "unos pendientes de lagofar [sic] =20rs." (Majadahonda, 1792); "un par de pendientes de argofar = 15rs." (Fuenlabrada, 1802); "un par de pendientes de Aljofar = 500rs" (Carabanchel de Arriba, 1803); "otros pendientes con ajofar $=50$ rs" (Villa del Prado, 1823); "...un par de pendientes de Aljofar..." (Vallecas, 1845).

Éstos parecen concentrarse en las comarcas al sur de la capital y algunos pueblos de su alfoz. Aunque no faltan menciones en pueblos de otras áreas, en estos últimos casos aparecen siempre en inventarios de

10 Véase M. ${ }^{a}$ Victoria LICERAS FERRERES, Indumentaria valenciana. Siglos XVIII-XIX. De dentro afuera, de arriba abajo (Valencia: Valencia Viva I, 1991), pp. 70-83.

11 LICERAS FERRERES, op. cit.

12 Véase M. ${ }^{a}$ Lena MATEU PRATS, Joyería popular de Zamora (Zamora: Caja de Ahorros, 1985), p. 41. 
familias acomodadas junto a prendas de carácter urbano: "unos pendientes de aljofar" (Zarzalejo, 1714), "un par de pendientes de tres gajos de oro y Aljofar que tiene puesto dha. Angela" (Lozoya del Valle, 1787). En las áreas predominantes parece que fueron muy populares y, excepto un caso: "un par de pendientes de Aljofar con sus Arillos de plata" (Alcorcón, 1764), siempre aparecen sobre soporte de oro:

"un par de pendientes de aljofar con arillos de oro $=75 \mathrm{rs}$ " (Pozuelo de Alarcón, 1750); “...unos pendientes de oro con unos Granos de Aljofar.... (Pinto, 1789); "unos pendientes de Aljofar, con arillos de oro = 20rs." (Majadahonda, 1791); "unos pendientes de aljofar con tres granos y arillos de oro $=50$ rs." (Chinchón, 1805); «...unos pendientes de Aljofar con arillos de oro.... (Cubas de la Sagra, 1809); etc.

En algunos lugares, como Carabanchel de Arriba, las descripciones son relativamente explícitas, y tan numerosas las referencias, que cabría señalar estos pendientes como característicos de las carabancheleras del ochocientos:

«...el Par de Pendientes que tengo buenos de Aljofar con arillos, palillos y granos de oro" (Carabanchel de Arriba, 1800); “...un Par de Pendientes pequeños de Aljofar, con granos, palillos y arillos de oro.... (Carabanchel de Arriba, 1800), "...Unos Pendientes de Alxofar con arillos, palillos y granos, de oro.... (Carabanchel de Arriba, 1800); "...y ademas unos Pendientes de Aljofar con arillos, y palillos de oro." (Carabanchel de Arriba, 1800); «unos Pend.tes de Aljofar, con arillos y Palillos de oro y cinco granos cada uno..." (Carabanchel de Arriba, 1801). "un Par de Pendientes de Aljofar, con Palillos y granillos de oro =60rs." (Carabanchel de Arriba, 1803).

Aunque no quede claro si los granos son de oro o de aljófar, estas descripciones recuerdan a los pendientes compuestos de arillo y palillo colgante con cuentas de aljófar engarzadas, de mayor abolengo, al menos en su aspecto formal. Compárese, por ejemplo, con algunos de la provincia de Zamora ${ }^{13}$ y que, según Antonio Cea, en Salamanca se denominan de chorro, o con las gallegas valencianas, también de aljófar. A veces se ci$\tan$ en los inventarios apuntados como arillos:

"un par de arillos de oro con granos de aljofar =60rs." (Navalcarnero, 1800); "unos arillos de oro grandes con unos granos de aljofar = 100rs." (Chinchón, 1805); «...un Par de Arillos de oro con tres granos de Aljofar cada uno, que yo tengo.... (Chinchón, 1805); "unos Arillos de Oro con Calabazitas de Aljofar = 180rs." (Pinto, 1827); “...unos Arillos de Aljofar, los que tengo puestos...” (Campo Real, 1846).

Recordemos la antigüedad de los pendientes en forma de aro, y apuntemos ahora otros que también como arillos, y por lo regular de oro,

13 Mateu Prats, op. cit. 
aparecen en los inventarios. Son abundantísimos en Chinchón y pueblos de su área: "unos Arillos de Oro=40rs." (Brunete, 1799); "unos arillos de oro = 30rs." (Carabaña, 1805); "unos Arillos de oro = 40rs" (Chinchón, 1807); "un par de arillos de oro" (Barajas de Madrid, 1837); "un par de arillos de oro $=30 \mathrm{rs} . "$ (Brea de Tajo, 1838); etc.

Respecto al uso del aljófar, sabemos por testimonios escritos lo popular que fue entre las villanas del XVII ${ }^{14}$. Más cercano en el espacio y en el tiempo, un escueto pero certero artículo sobre indumentaria tradicional en Guadalajara, publicado a mediados del presente siglo, nos dice, refiriéndose al aderezo de las alcarreñas de la comarca de Pastrana, frontera suroriental de la provincia de Madrid: "Las joyas son poco suntuosas: pendientes de aljófar, algún broche y collar fino y corto de aljófar o cuentas de metal" [... $]^{15}$.

En Madrid, hasta la fecha, no hemos encontrado ninguna pieza para cotejar con las de otras provincias, así es que apuntamos estos datos con vistas a posteriores pesquisas.

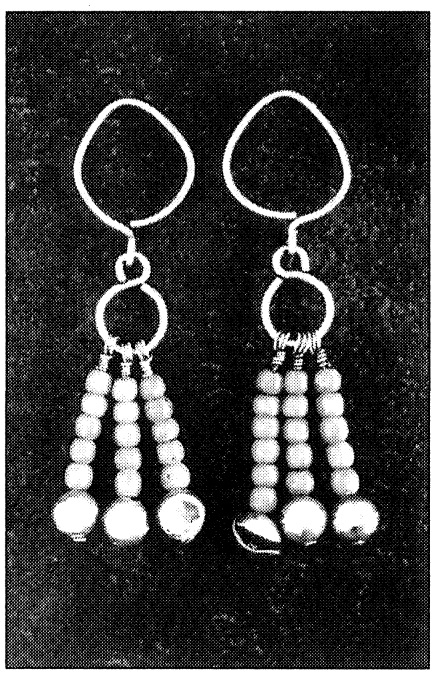

FIG. 3.-Pendientes. San Martín de Valdeiglesias. Col. Museo del Pueblo Español de Madrid (núm. inv. 7004).
En estrecha relación formal con todos estos pendientes circulares o zarcillos, se conservan unos en el Museo del Pueblo Español de Madrid, procedentes de San Martín de Valdeiglesias. Son de plata y de tosca factura, de carácter muy tradicional. Aunque los granos que cargan los tres palillos, que lleva cada uno no sean de aljófar sino de coral, no podemos evitar la comparación al leer las referencias antes citadas (Fig. 3). Y aprovechamos para pasar así a los pendientes más característicos del siglo XIX: los de coral.

Parece ser que hacen su aparición con la moda romántica, hacia los años 30 de ese siglo. Se popularizan con rapidez, y así, los vemos en los grabados decimonónicos adornando las orejas de mujeres de todas las clases sociales y regiones. En Madrid fueron tan usuales que aún hoy son recorda-

${ }^{14}$ Véase Jose AlCAlÁ-ZAmora y Otros, La vida cotidiana en la España de Velázquez (Madrid: Temas de Hoy, 1989), p. 67.

15 Sinforiano GARCía SANZ, "Notas sobre el traje popular en la provincia de Guadalajara", RDTP, VII (1951), pp. 141-151. 


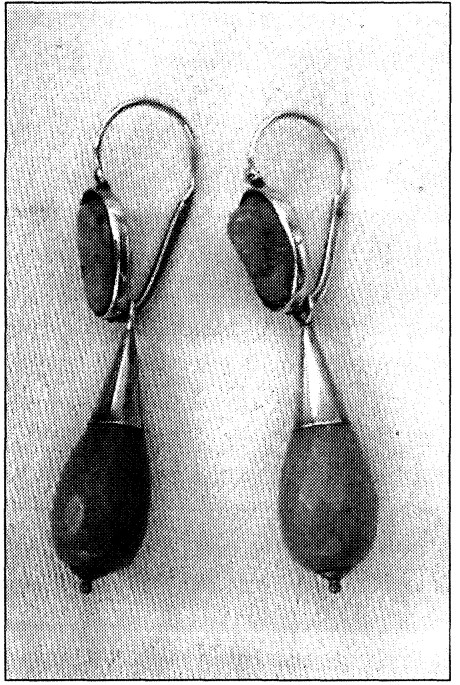

FIG. 4.-Pendientes de coral. Chinchón. $5 \mathrm{~cm}$.

dos vivamente por cuantas informantes hemos consultado. Se componen invariablemente de un botón de coral engastado en oro bajo o similor tallado con la figura de un perfil humano; en Villarejo de Salvanés llaman caras a este cuerpo y aseguran que en cada par de pendientes se distinguen macho y hembra. De este botón pende un colgante de coral en forma de lágrima -que denominan perilla en Villamanta, Villarejo y Guadalix de la Sierra y calabaza en Chinchón- que puede ser lisa o trabajada en facetas romboidales; así tallados los hemos visto en Chinchón (Fig. 4) y Venturada. En algunos lugares, como Villarejo de Salvanés, son usados aún hoy a diario por algunas mujeres de edad, aunque muchas de ellas los han desprovisto de las perillas, ya que las más antiguas solían ser de gran tamaño y les dañarían los lóbulos.

"unos pendientes de similor con calavacitas de corales $=16$ rs." (Cubas de la Sagra, 1816); "un par de pendientes de coral encarnado con broches de oro" (Barajas de Madrid, 1837); "un par de pendientes de coral = 60rs." (Valdetorres de Jarama, 1837); "un par de pendientes de Coral =50rs." (Torrejón de Ardoz, 1838); "un Collar y pendientes de coral fino con engarce de oro $=400$ rs." (Nuevo Baztán, 1839); "Otros pendientes de coral $=21$ rs." (Vicálvaro, 1842); "un par de pendientes de Coral $=40 \mathrm{rs}$. ." (Vallecas, 1842); "dos pares de pendientes, unos de coral y otros de oro $=90$ rs." (Villarejo de Salvanés, 1843); "un par de pendientes de coral engarzados en oro $=60$ rs." (Pinto, 1844); "un par de pendientes de oro con camafeos y perillas de coral $=40 \mathrm{rs} . "$ (Navalcarnero, 1847); "unos pend.tes de coral $=38 \mathrm{rs} . "$ (Villaconejos, 1851); "un par de pendientes de coral =60rs." (Majadahonda, 1853); "dos pares de pendientes de oro con corales $=90 \mathrm{rs}$. ." (Pozuelo de Alarcón, 1855); "Par de pendientes de coral = 50rs." (El Álamo, 1855).

Acusando esta forma de botón y calabacilla, pero sin especificar el material de esta última, parecen también algunos de los inventariados: "unos Pendientes de calabacillas, con flores dentro" (Colmenar de Oreja, 1798); "tres pares de pendientes, los dos de calabacillas $=35$ rs." (Navalcarnero, 1802); "unos pendientes de oro con calabacitas de color de lila $=24 \mathrm{rs}$." (San Martín de la Vega, 1830); "un par de pendientes de oro figura de Calabaza $=160$ rs." (Vallecas, 1846); etc. 
Abundantísimas son las referencias en todas las épocas a pendientes de oro, sin más especificación, siendo imposible hacer ninguna conjetura sobre su hechura:

"unos pendientes de oro" (San Lorenzo del Escorial, 1807); "unos Pendientes de Oro = 80rs." (Leganés, 1810); "unos pendientes doro = 50rs." (Fuenlabrada, 1817); "un par de Pendientes de oro = 30rs." (San Martín de Valdeiglesias, 1820); "Mando á mi herm. ${ }^{a}$ [...] unos pend.tes de oro..." (Colmenar de Oreja, 1823); "un par de pendientes de oro $=28 \mathrm{rs}$." (Navalcarnero, 1824); "un par de pendientes de oro =48rs." (San Martín de la Vega, 1829); "Otros pendientes de oro = 38rs." (Valdeavero, 1834); "...unos pendientes de oro" (Estremera de Tajo, 1834); "unos pendientes de oro = 20rs." (Santorcaz, 1834); "unos pendientes de oro = 16rs." (Algete, 1834); "un par de pend.s de oro = 26rs." (Barajas de Madrid, 1835); "unos pendientes de oro = 30rs." (Torrejón de Ardoz, 1837); otros pendientes de oro = 30rs.n (Corpa, 1837); "Mando a María del Carmen Auñon dos pendientes de oro..." (Valdetorres del Jarama, 1837); "unos pendientes de oro = 16rs." (Campo Real, 1837); "unos pendientes de oro $=18 \mathrm{rs."} \mathrm{(Chinchón,} \mathrm{1840);} \mathrm{"...y} \mathrm{los} \mathrm{pendientes} \mathrm{de} \mathrm{oro} \mathrm{que} \mathrm{usa} \mathrm{la}$ otorgante..." (Buitrago del Lozoya, 1841); "unos pendientes de oro = 26rs." (Villarejo de Salvanés, 1844); "unos pendientes de oro=44rs." (Cubas de la Sagra, 1845); "un par de pendientes de oro $=30$ rs." (Vallecas, 1846), "un par de pendientes de oro =10rs." (Perales de Tajuña, 1849); "unos pendientes de oro $=5$ rs." (Valdaracete, 1872).

En muy pocos casos se pueden inferir medianamente sus formas o elementos de que se componen: "unos Pendientes afiligranados de Oro" (Villamanta, 1805), "unos Pendientes de oro de aro con su voton $=26 \mathrm{rs}$." (Algete, 1834); "unos pendientes de oro redondos = 40rs." (San Lorenzo del Escorial, 1837), "unos pendientes de oro labrados $=60$ rs." (Carabaña, 1839), "un par de pendientes lisos de oro $=20$ rs." (Vallecas, 1842). Las referencias a arracadas son algo más explícitas sobre las hechuras: "dos Arracadas de oro el reberso tablado Picado, y encasquillado liso $=451 \mathrm{rs}$., y el oro q.e tiene $=50 \mathrm{rs."} \mathrm{(Cubas} \mathrm{de} \mathrm{la} \mathrm{Sagra,} \mathrm{1798),} \mathrm{"dos} \mathrm{Arracadas} \mathrm{de} \mathrm{oro,}$ comp.tas de los broquelillos, y dos almendras, con dos colgantillos $=154 \mathrm{rs}$." (Braojos, 1800), "dos Arracadas de Oro = 118rs." (Arganda del Rey, 1813).

Otro tipo de pendientes que encontramos con cierta frecuencia en los protocolos son los broquelillos. La definición que da de ellos el Diccionario de Autoridades es ésta: "Además del sentido recto, que es diminutivo de Broquél, se llama también assi el botoncillo de que está pendiente la piedra, almendra, ó pendientes de los perendengues, ó arracadas, con que se adornan las oréjas las mugéres" ${ }^{16}$.

Pero en los inventarios madrileños parece ser pieza exenta, sin que aparezca por ningún lado el resto de los cuerpos que compondrían el

16 Diccionario de Autoridades (1726-1737) (Ed. fac., Madrid: Gredos, 1969). 
pendiente completo. Algunos autores han señalado los pendientes de un solo cuerpo en forma de roseta como degeneración de última hora de los de dos y tres cuerpos ${ }^{17}$, pero en algunos cuadros del pintor napolitano Lorenzo Tiépolo, pintados en Madrid hacia 1770, aparecen varias mujeres del pueblo llano de la Villa luciendo estas rosillas o botones de pequeño tamaño. Por tanto, cabe pensar que también los usaran las campesinas de los pueblos cercanos a la Corte, y quizá a ellos debamos mirar cuando encontramos broquelillos en los protocolos:

"un broquelillo con boton de oro = 40rs." (El Álamo, 1790); "unos Broquelillos de Plata $=22$ rs." (Majadahonda, 1790); "unos broquelillos de piedras $=20$ rs." (Cubas de la Sagra, 1798); «unos Broquelillos de diamantes en oro con falta de algunos de ellos, y tres granos de Aljofar cada uno" (Navalcarnero,1800); "unos Broquelillos de Piedras de Francia $=20$ rs." (Leganés, 1803); "unos Broquelillos $=25$ rs." (Villamantilla, 1810); "tres vroquelillos de oro $=20$ rs" (Villa del Prado, 1823); "tres pendientes de oro broquelillos $=60$ rs.n $($ Chinchón, 1840) .

Finalmente, hay que reseñar algunos pendientes de uso popular observados en el trabajo de campo, de formas menos características, probablemente de finales del siglo XIX.

\section{COLLARES Y GARGANTILLAS}

Complemento indispensable del atuendo femenino eran las sartas alrededor de la garganta. En los grabados y fotografias del siglo XIX aparecen las campesinas madrileñas, de la montaña o de la campiña, con unas breves vueltas, por lo común nunca más de dos, rodeando el cuello. Y poco más; el sencillo aderezo de las mujeres del pueblo consistía normalmente en un par de pendientes y una gargantilla de cuentas de pasta vítrea. Estas gargantillas están aún vivas en la memoria de las gentes. El hecho de que la mayoría de las que se recuerden sean las de color negro quizá obedezca a que ya sólo las usaban personas de edad, que por guardar luto generalmente abandonaban el colorido. Aún así, nos hablaron de gargantillas de cuentas coloradas (Guadalix de la Sierra, Valdaracete), azules (Miraflores), negras y verdes (Montejo de la Sierra) o blancas (El Boalo, Guadalix, Robledondo). En este último pueblo recordaban unas de cuentas facetadas de vidrio blanco, de dos vueltas, a las que llamaban gargantillas de chino (por los chinos o piedras que las componían). Todas estas gargantillas se ajustaban, por lo general, por medio de unas cintitas de

17 Mateu Prats, op. cit. 
color que se anudaban detrás o al lado del cuello. Se solían llevar siempre bastante apretadas y por dentro del pañuelo de los hombros, de manera que se entrevieran por la abertura superior de éste. De este modo aparecen las de las serranas de Sieteiglesias que acudieron a Madrid con motivo de la boda de Alfonso XII, conocidas por los retratos que de ellas hiciera Laurent, así como las de varios grabados de tipos de otras zonas de la provincia. Ocasionalmente, podían llevar una cruz o una recortada medalla de plata de alguna devoción local; así nos contó una informante de Colmenar Viejo cómo su madre gastaba una gargantilla negra de dos vueltas con una medallita de la Virgen de Remedios.

Los collares y gargantillas se citan poco en los protocolos, y en ellos los más frecuentes son los de aljófar. Valgan pues los mismos comentarios que hicimos en el caso de los pendientes, sobre su difusión geográfica y frecuencia de aparición en los inventarios.

"un Collar de Aljofar de una buelta" (Pinto, 1789); "un collar de cinco Illos y en ellos Quatrocientos sesenta y cinco granos de Alxofar de genero de cadenilla, y entre ellos algunos algo asentado y otros aperlados $=876 \mathrm{rs}$." (Cubas de la Sagra, 1798); "un collar de Aljofar" (Estremera de Tajo, 1798); "un Collar de Aljofar granada de cinco bueltas" (Navalcarnero, 1800); "...un Collar de Aljofar de una buelta con un Corazon berde.... (Brunete, 1801); "un collar de aljofar de dos bueltas $=300$ rs." (Chinchón, 1805); "un Collar de Aljofar = 160rs." (San Martín de Valdeiglesias, 1820); "...un Collar de Aljofar con sus pendientes correspondientes...." (Colmenar de Oreja, 1825); "Así mismo mando un Collar de Aljofar de cinco a seis bueltas a mi Nieta Alejandra..." (Vallecas, 1845).

De nuevo parece haber en Carabanchel un especial gusto por estas perlas irregulares y de poco valor; collares de hasta seis vueltas se repartían a veces en las mandas testamentarias: "...el collar de Aljofar de seis bueltas el que partiran entre los dos como buenos hermanos..." (Carabanchel de Arriba, 1800); "un collar de Aljofar menudo = 225rs." (Carabanchel de Arriba, 1803).

Entre las gargantillas también aparecen bastantes de este material:

"una Gargantilla de Aljofar" (Pinto, 1789); aun par de gargantilla de azofar [sic] de una buelta con pendientes correspondientes de un gallo $=40 \mathrm{rs} . "$ (Colmenar de Oreja, 1800); «una Gargantilla de Aljofar con su cruz de lo mismo; una Joya de Aljofar en oro; otra Gargantilla de Aljofar que es la que se trajo de casa de mi séñora [...] y una Buelta de Aljofar" (Chinchón, 1806); "Mando a Isabel Recio, soltera, mi sobrina [...] una Gargantilla de Aljofar" (Chinchón, 1841).

Además de la referencia ya citada de la provincia de Guadalajara, también las alcaldesas de Zamarramala (Segovia) incorporan unas gargantillas de aljófar entre su recargado aderezo. 
Menos frecuentes en los inventarios son los collares de coral, tan del gusto popular en amplias regiones de la península. Son raros en documentos anteriores a 1820. Excepto en dos casos que parecen describir coraladas de carácter netamente tradicional: "un Collar de Corales con una medalla de nuestra Señora del Pilar $=8$ rs." (Pozuelo de Alarcón, 1750), "un collar de coral, con seis bueltas y una medalla de plata $=44 \mathrm{rs} . "$ (Fuenlabrada, 1842), en el resto la aparición de broches de oro para atarlos parece indicar que se trataba de joyas de carácter más urbano: "un collar de coral con broches de oro $=50$ rs." (Torrejón de Ardoz, 1834), "un collar de Coral con broches de oro $=60$ rs." (Torrejón de Ardoz, 1838), "un collar de coral con broche de oro $=80$ rs." (San Lorenzo del Escorial, 1840). Se observa una cierta abundancia en los pueblos ribereños del Henares y Jarama medio. Alguna monografía local de la zona reseña el recuerdo del uso de collares de ese material ${ }^{18}$. Otros ejemplos de collares y gargantillas de coral son, casi siempre, posteriores a la fecha que antes apuntábamos:

"una Gargantilla de coral = 8rs." (Chinchón, 1809); "un collar imitado á coral = 10rs." (Navalcarnero, 1824); "un Collar de Corales con una Palomita de oro $=40 \mathrm{rs} . "$ (Algete, 1834); "un Collar de Coral = 20rs." (Barajas de Madrid, 1837); "un collar de Coral = 40rs." (Navalcarnero, 1845); "un collar de corales" (Móstoles, 1849).

Los collares de cuentas de pasta vítrea de los que hablábamos más arriba están ausentes en los inventarios, acaso porque fueran utilizados por mujeres más modestas que no usaran de escribanos para sus dotes. De la Sierra Norte, donde por testimonios orales sabemos que estas gargantillas fueron muy populares, tan sólo hemos encontrado estas escuetas referencias: "A Catalina Mrn. mi Sobrina la Mantilla blanca de vayeta, los collares blancos y un pañuelo de munsulina..." (Lozoya del Valle, 1785), "A la Margarita las gargantillas buenas..." (Pinilla de Buitrago, 1831).

Otros materiales menos frecuentes y representativos de diferentes niveles económicos son, por orden de la cantidad en que se citan: las perlas, el nácar, el ámbar, el abalorio (?) y los granates.

PERLAS: "un Collar de Perlas el mejor que tenía" (Pinto, 1789); "un collar de perlas falsas gordas $=6$ rs." (Chinchón, 1805); "dos collares de perlas gordas $=4 \mathrm{rs} . "$ (El Álamo, 1789). NÁCAR: "quatro collares el uno de Nacar = 20rs." (El Álamo, 1790); "un Collar de Nacar = 24rs." (Majadahonda, 1791). ÁMBAR: "un Collar de Ambar" (Pinto, 1841). ABALORIO: "Dos collares de Abalorio = 4rs." (Santorcaz, 1836); "un collar de abalorio $=6$ rs." (Villaconejos, 1853). GRANATES: "tres collares de granates $=10$ rs." (Cubas de la Sagra, 1794); un collar de granates, con un coraz.n de Marquesitas $=62$ rs." (Colmenar de Oreja, 1768).

18 Véase Miguel Alcobendas FernÁndez, Crónicas de Algete (Madrid, 1995), pp. 101-102. 
Pero lo que gozó de verdadera popularidad -al menos durante el siglo XVIII y primeras décadas del xIX - como adorno de la garganta fueron las cruces y las piezas del cuello.

\section{CRUCES Y DEMÁS PIEZAS DEL CUELLO}

Ya dijimos al hablar de los aderezos dieciochescos cómo estos solían componerse como mínimo de pendientes y alguna pieza para el cuello. En Madrid aparecen especialmente cruces, seguidas de las que llaman palomitas, y también corazones, lazos, medallones, piezas y floreros. Todas estas piezas seguramente guardarían analogías con las que hoy se conservan en otras regiones de España. Ninguna de ellas parece ser recordada por nuestros informantes, con excepción de las cruces de Caravaca, que llevaban las mujeres de Estremera colgadas de una cinta negra. Entre las cruces predominan las de piedras francesas engastadas en plata:

"una cruz de piedras de Francia en plata = 20rs." (El Álamo, 1790); "una Cruz de piedras de Francia" (Pinto, 1790); "una Cruz de Plata, con piedras berdes $=8 \mathrm{rs}$." (Majadahonda, 1791); "una Cruz de Piedras de Francia = 40rs." (Carabanchel de Arriba, 1803); "una cruz de Plata con piedras = 20rs." (Carabaña, 1804); "Mando á mi hermana, Maria theresa orcaxo [...] una Cruz de plata con piedras.... (Estremera de Tajo, 1804); "una Cruz de plata con piedras de Francia $=30$ rs." (San Lorenzo del Escorial, 1808); "...una Cruz de piedras de Francia" (Valdaracete, 1813); "una cruz de plata con piedras de Francia $=20$ rs." (Cubas de la Sagra, 1816).

También las hay de plata sola: "una Cruz de plata $=40$ rs." (Carabanchel de Arriba, 1800); "Lego y Mando á mi Nieta Maria Agudo, dos medallas y una Cruz de plata que tengo..." (Villamanta, 1802).

Seguramente todas estas cruces formarían conjunto con los pendientes y arracadas anteriormente citados, y junto a ellos aparecen muchas veces en los inventarios:

"una Cruz con sus pendientes $=49 \mathrm{rs} . "$ (El Álamo, 1791); "Cruz y pendientes de plata $=23$ rs." (Valdemorillo, 1794); "una Cruz, y Arracadas de Piedras de francia en plata $=40$ rs." (Brunete, 1798); "una cruz de piedras de francia con sus pendientes $=70 \mathrm{rs} . n$ (Colmenar de Oreja, 1803); «una Cruz de plata con piedras y pendientes $=30$ rs.. (Carabaña, 1804).

Sobre el uso de estas cruces como adorno del cuello, los protocolos no ofrecen ninguna duda; incluso alguna vez destacan su utilización diaria:

"tres Cruces de plata para el Cuello guarnecidas de piedras falsas $=75 \mathrm{rs}$." (Pozuelo de Alarcón, 1776), “...y una Cruz de Plata para el Cuello, engastada de Piedras 
Encarnadas, que tengo..." (Majadahonda, 1787), "una Cruz de Piedras diaria $=$ 5rs." (Valdemorillo, 1791), "una Cruz de pescuezo = 6rs." (Fuenlabrada, 1802), "Mando á Isavel Alcolea la Cruz q.e Uso al Cuello p. ${ }^{a}$ Spre. jamas." (Estremera de Tajo, 1804).

Tampoco faltan los comentarios sobre su estructura y forma. En algunos casos, parece que la cruz pendía de otro cuerpo que se nombra botón o rosilla, y a veces del clásico lazo. Cruces como estas se han encontrado con profusión en otras provincias ${ }^{19}$ :

"una Cruz para el Cuello de plata con piedras de francia con su Cavezera $=60 \mathrm{rs}$, " (Alcorcón, 1765), un Adrezo de Diamantes en Plata compuesto de cruz, trecho y un Lazo que sirbe de Pasador con sus Arracadas correspondientes" (Estremera de Tajo, 1770), "una Cruz y voton de piedras ordinarias = 10rs." (Chinchón, 1805), "una Cruz con su Pieza y Boton de rosilla $=170$ rs." (Arganda del Rey, 1813).

Además de las cruces se encuentran otras piezas, a veces nombradas así en los inventarios: "una Pieza del Pescuezo de piedras de francia" (Brunete, 1799), "una Pieza de Oro para la Garganta $=33$ rs." (Arganda del Rey, 1813). Las más extendidas son las palomitas o palomillas. Acaso aludan a cierto tipo de adorno del cuello, dieciochesco, que recuerda vagamente a un ave con las alas abiertas. "Palomita" dicen también en muchos pueblos de la provincia a las mariposas nocturnas, cuya silueta también es similar a la de los conocidos lazos de aderezo. Las citas son numerosas:

"Mando á Luisa Paris hija de Gabina Paris, Una Palomita y Pendientes de Plata para siempre.... (Villarejo de Salvanés, 1796); "un Aderezo de Cruz y Pendientes y una Palomilla p. ${ }^{a}$ el cuello todo de plata $=51 \mathrm{rs}$. " (Estremera, 1758), "Mando por una vez (...) á mi Nieta una palomilla de plata p. ${ }^{a}$ el Cuello q.e tengo, y la pido...n (Brunete, 1800), "una palomita de piedras de francia $=10$ rs." (Fuenlabrada, 1802); "una palomilla de plata con una piedra falsa verde enmedio $=6 r s "$ (Pozuelo de Alarcón, 1803), «una Palomita de Plata p. ${ }^{a}$ el Cuello = 24rs" (Villamanta, 1810); "una palomilla con lazo de piedra y cerco de plata" (Santorcaz, 1833).

Más raros, pero en relación con las palomitas, son los lazos: «un lazo del cuello con Piedras encarnadas y Una Berde enmedio y otra Blanca empeñado por veinte rs." (Valdemorillo, 1793), "un Lazo para el cuello de piedras $=8$ rs." (Chinchón, 1805), "un Lazo para el Cuello de Plata y Piedra $=40$ rs.n (Villamanta, 1810). También aparece alguno en Fuenlabrada y Navalcarnero (1802) y en Villarejo de Salvanés (1817).

Relativamente numerosos son los corazones de plata, a veces afiligranados, tan del gusto popular: "un Corazon de Feligrana para el cuello y

19 Francisco ZANÓN RODRIGO, “Las joyas: una aportación a la indumentaria valenciana (1801-1809)», Torrens, (1982), pp. 129-176. 
dos botones de plata para los puños $=20 \mathrm{rs"} \mathrm{(El} \mathrm{Álamo,} \mathrm{1790),} \mathrm{"un} \mathrm{cora-}$ zón para el cuello de Piedras de Plata de Francia $=50$ rs." (Colmenar de Oreja, 1798), "una cruz, un alfiletero, dos medallas y un corazón afiligranado $=70$ rs." (Torrejón de Velasco, 1837). Otros corazones se citan en Fuenlabrada (1802), Cubas de la Sagra (1794), Valdaracete (1816), Chinchón (1809), Navalcarnero (1800), Brunete (1801) y Vallecas (1842).

Los medallones, quizás aludan a algún tipo especial de relicario o dije de vidriera: "un Medallon para el cuello=10rs." (El Álamo, 1797); "un Medallon de piedras de Francia con guarniz.on de perlas doradas $=100$ rs." (Brunete, 1801), etc. Medallones se nombran también en Cubas de la Sagra (1794), Pinto (1827), Navalcarnero (1824).

Otras piezas, cuyas características desconocemos, aparecen bajo el nombre de floreros o el genérico de joyas: "un florero de el cuello $=6 r s . "$ (El Álamo, 1799), "dos floreros de piedras de Francia $=40$ rs." (Navalcarnero, 1802), "un Premio, o florero, embutido en Plata p. el cuello $=80 \mathrm{rs}$. ." (Villamanta, 1805), etc; y entre las joyas: "dos joias $=30$ rs." (El Álamo, 1791), "una Joya de oro afeligranada, y un collar de Aljofar $=300 \mathrm{rs}$. ." (Estremera, 1798), "una Joya de Aljofar" (Brunete, 1801), etc. Destaca la alta frecuencia de aparición de todas estas piezas en los pueblos cercanos a los antiguos Caminos de Extremadura y Toledo.

\section{MEDALLAS}

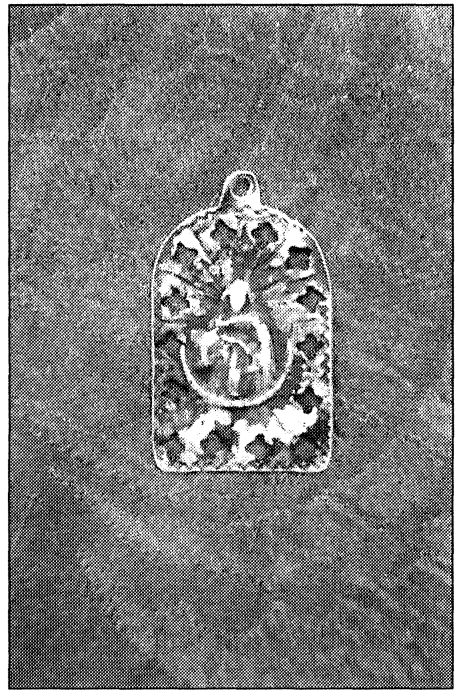

FIG. 5.-Medalla de la Purísima. Estremera de Tajo. $3 \mathrm{~cm}$.
Las medallas de plata recortada son de gran tradición en el adorno de garganta y pecho de mujeres de toda condición social o económica. Los inventarios están repletos de referencias a manojos de medallas de diversos materiales, comúnmente de plata. Todavía hoy son recordadas en la mayoría de los pueblos (Fig. 5), ya sea formando parte de gargantillas y rosarios, ya prendidas en una cinta de velludillo negro muy apretada al cuello, como nos contaron en Valdemanco. Entre las diferentes figuras y advocaciones aparecidas en el material de archivo, cuando se especifican, daremos las más nombradas ordenadas en atención a la frecuencia con que son citadas. Entre las advocaciones de vírgenes, ocupa el primer 
lugar la del Sagrario de Toledo (10 ejemplos), seguida por la del Pilar de Zaragoza (6 ejemplos), Guadalupe (3 ejemplos) y Nieva (2 ejemplos); el Prado de Talavera, Carmen, Concepción y Gracia están representadas con un ejemplo cada una. En Valdemanco se recuerdan medallas de la Virgen de Valdejimena (Salamanca), protectora contra la rabia. De santos y santas: San Miguel, San Ildefonso, Santa Bárbara, San Antonio, Santa Teresa y Santa Gertrudis. En alguna ocasión se señala su uso específico para determinadas ceremonias: uuna Medalla de Plata para como es costumbre ponersela el dia de la Boda $=26 r s . "$ (Majadahonda, 1791); también aparecen cosidas a prendas: "un justillo de pana con una medalla $=16 \mathrm{rs."} \mathrm{(San} \mathrm{Martín} \mathrm{de} \mathrm{la} \mathrm{Vega,}$ 1826). Veamos algunos ejemplos:

"siete medallas de Plata de varios tamaños = 79rs." (Estremera de Tajo, 1798); "una Medalla de plata, Imagen de Nra. Señora de la Concepcion" (Navalcarnero, 1802); "una medalla del Sagrario de Plata Suelta = 20rs." (Villamanta, 1805); "una Medalla de Nra. Sra. de Nieva de Plata = 20rs." (Buitrago del Lozoya, 1805); "ocho Medallas de Plata sobre doradas $=40 \mathrm{rs."} \mathrm{(Santorcaz,} \mathrm{1836);} \mathrm{"un} \mathrm{manojo} \mathrm{de}$ medallas $=20$ rs." (El Escorial de Abajo, 1840); etc.

\section{RELICARIOS Y OTROS DIJES}

Fue costumbre de las mujeres españolas colgar relicarios del cuello o la cintura. La Condesa d'Aulnoy apuntó lo chocante de este uso, que a juzgar por la sorpresa que le causó, debía ser desconocido en la Francia de aquellos años: "Llevan cinturones llenos de medallas y de relicarios. Hay muchas iglesias que no tienen tantos. [...] Llevan Agnus Dei y pequeñas imágenes sobre sus mangas, sus hombros y por todas partes [...] ${ }^{20}$.

Sorprende la cantidad de relicarios aparecidos en los inventarios, y aún más el hecho de que semejante compostura no llamase la atención de escritores y dibujantes en el siglo XIX. Pudiera pensarse que fue debido a que estos dijes - como también se nombran - no se llevasen realmente al cuello; así se apunta en algún testamento: "Mando á d. ${ }^{a}$ Teresa Blanco, muger del d.n Bernardino, un relicario grande de plata, el mayor; á su hija Maria otro mas mediano; $Y$ á su hijo Josef otro que tengo en la faldriquera, y una medalla..." (San Lorenzo del Escorial, 1812). Sin embargo, conocemos por referencias orales y algunas viejas fotografías la costumbre de traer los relicarios al cuello las campesinas, ya sea suspendidos de una cadena, ya sujetos con una cinta maja de seda. En el caso de Robledondo, nos contaron cómo las antiguas se colgaban un medallo —que así llaman allí a los relicarios de vidriera- de una cinta de seda

20 D'Aulnoy, op. cit., pp. 235-236. 


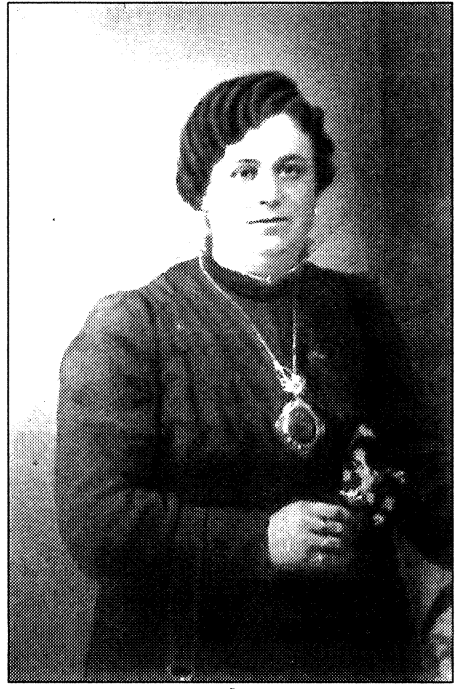

FIG. 6.-María del Carmen García Navarro, de Valdaracete, luciendo un relicario al pecho, hacia 1880 . (Gentileza de María Navarro García-Porrero) multicolor. Así lo atestiguan unas fotografías tomadas por F. Andrade hacia 1930; sabemos por una de las modelos, a la que tuvimos ocasión de conocer, que en aquella ocasión su madre las vistió a ella y a sus hermanas a la antigua usanza para que "un señor de Madrid las retratasen. Pueden verse, además de los suspendidos sobre el pecho, otros prendidos al pañuelo sobre los hombros, con una lazada de cinta de color (Figs. 6 y 7). Así acompañados de su cinta se citan los dijes en los inventarios; incluso volvemos a encontrar alguno de uso específico como parte del vestido para la boda:

"un dije de plata con su lazo de cinta plateada $=48 \mathrm{rs} . "$ (El Álamo, 1791), "del Dige y cinta $=26 \mathrm{rs} . "$ (Majadahonda, 1792), "un dixe con engarze de Plata con su cintillo $=40$ rs." (Cubas de la Sagra, 1794), "un dixe para la boda con su cinta $=30$ rs."

(El Álamo, 1797), uun dije guarnecido de Plata con Bidriera y un lazo encarnado de Sn. Geronimo $=20$ rs." $\left(\right.$ Villamanta, 1810) ${ }^{21}$.

Digamos de paso que sólo hemos tenido en cuenta aquellos relicarios que en los inventarios aparecen entre la ropa, dando a entender su utilización, a nuestro juicio, como parte integrante del traje, a diferencia de los citados junto a los muebles de sala, vitrinas y escaparates, tasados en un precio más elevado. Pocas veces se apuntan las imágenes que representan o su contenido, excepción hecha de los lignum crucis. Entre las advocaciones de la Virgen, hallamos las del Pilar, Sagrario, Rosario, Soledad, de la Leche, de Belén y Dolores; y de los santos y santas,

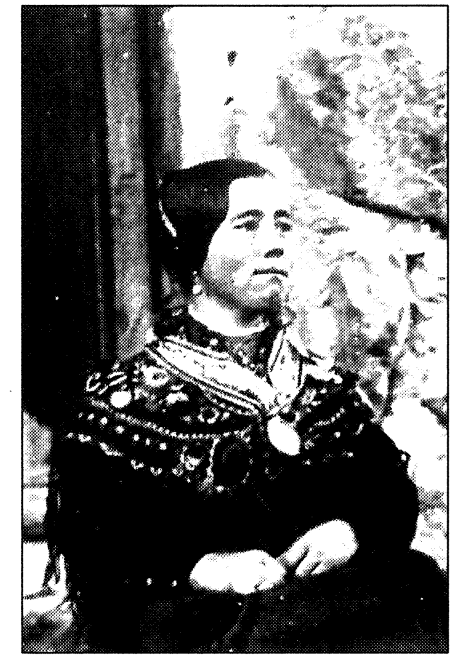

FIG. 7.-Serrana de Robledondo, hacia 1930. (Fot. F. Andrade).

21 En Gargantilla del Lozoya recordaban el uso de dijes con retrato y vidriera, colgantes del cuello mediante una cadena dorada. 
Santa Teresa, San Francisco, San Antonio Abad y San Antonio de Padua, San Juan de la Cruz, San José, San Juan Evangelista, San Luis, Santa Rosa y San Isidro, además de imágenes del Niño Jesús y el Nazareno; incluso aparece un relicario "con la figura del papa" (El Álamo, 1790). Muy usual era que combinaran diferentes imágenes en sus dos caras: "un Relicario con la Imagen de San Juan de la Cruz, y Sta. Theresa, con Cerco de plata sobredorado, afeligranado = 16rs." (Braojos, 1800), "un Relicario grande con las Imagenes de Sn. Antonio Abad, y Sn. Juan con engaste de plata de feligrana = 14rs." (Pozuelo de Alarcón, 1803). Por lo general están engastados en plata, aunque ocasionalmente se citan los de oro:

"un Relicario de Sn. Josef con Cerco de Plata $=14 \mathrm{rs}$. (Cubas de la Sagra, 1798); "un Relicario afiligranado $=20$ rs." (Navalcarnero, 1802); "Otro Relicario mediano con engaste de plata obalado = 12rs." (Pozuelo de Alarcón, 1803); "un Relicario engarzado en plata $=24 \mathrm{rs} . "$ (Carabanchel de Arriba, 1803); "un Relicario de N. S. ${ }^{a}$ de Belen con una Buelta de Aljofar alrededor que tengo..." (Chinchón, 1805); "un Relicario de plata feligranado $=10 \mathrm{rs.}$. (San Lorenzo del Escorial, 1808); "un relicario de plata sobredorado $=20$ rs." (Torrelaguna, 1809); "un Relicario con cerco de azero $=4$ rs." (San Martín de la Vega, 1828).

Más abundantes son los Agnus Dei - de los que hablaba Madame d'Aulnoy-, los lignum crucis y, sobre todo, las Caras de Dios, que solían representar la Santa Faz de Alicante o, más comúnmente, el Santo Rostro de Jaén:

AGNUS DEI: "...y dos Relicarios de Plata con un Agnus el uno..." (Pinto, 1789); "un agnus dei $=6$ rs." (Arganda del Rey, 1808); "un agnus engarzado en plata $=20 \mathrm{rs}$. " (Cubas de la Sagra, 1816); etc. LIGNUM CRUCIS: "un lignum crucis engarzado en plata $=40 \mathrm{rs."}$ (El Álamo, 1795); "un lignum Crucis de azero $=60 \mathrm{rs.}$." (Arganda del Rey, 1808); "un Ninum Cruzis [sicl y Una Cara de Dios = 40rs." (Pinto, 1828); "tres relicarios compuestos, un Sn. Ant. ${ }^{\circ}$, un Lignum Crucis, y una Cara de Dios $=30$ rs." (Vallecas, 1842); etc. CARA DE DIOS: "una Cara de Dios con engarze de Feligrana $=12$ rs. (Cubas de la Sagra, 1794); "una Cara de Dios de Plata feligranada $=20$ rs." (Estremera de Tajo, 1798); "un Relicario de la Cara de Dios con engaste de plata $=10$ rs." (Pozuelo de Alarcón, 1803); "una Cara de Dios = 6rs.» (Corpa, 1838).

Medallas, relicarios y medallones se citan muchas veces con sus correspondientes cadenas de oro o plata para colgar al cuello: "una cadena de plata sobre dorada con su medallon y pendientes de lo mismo $=270$ rs." (Arganda del Rey, 1809); "una Cadena de Plata con medalla = 50rs." (Villarejo de Salvanés, 1818); "una Cadena de oro con un relicario $=2500$ rs." (Pinto, 1827); "una Cadena Dorada con un Medallon = 100rs." (Corpa, 1837); "Otra Cadenita en concepto de plata sobredorada con un relicario de oro $=30 \mathrm{rs}$." (Vallecas, 1842). 


\title{
LOS ROSARIOS
}

De origen posiblemente oriental, según algunos autores ${ }^{22}$, el rezo del rosario alcanzó gran difusión en la época de la Contrarreforma, como expresión exteriorizada de piedad. En este tiempo se constituyen muchas de las cofradías que aún hoy subsisten en muchos lugares de España dedicadas a propagar su devoción. Tanto se prodigó su uso, que llegó a convertirse en una de las "cosas de España". De nuevo es Madame d'Aulnoy quien nos refiere:

\begin{abstract}
Es una cosa de ver el uso contínuo que hacen ellas de su rosario, llevando todas las señoras uno sujeto a la cintura, tan largo que no le falta mucho para que arrastre por el suelo. Lo van rezando sin cesar por las calles, cuando están jugando a las cartas y cuando están hablando, incluso cuando enamoran, cuentan mentiras o murmuraciones; porque se pasan la vida marmoteando sobre su rosario, y cuando hay muchas reunidas, eso no impide el que lo sigan diciendo. Os dejo imaginar lo devotamente que lo harán; pero la costumbre es muy poderosa en este país ${ }^{23}$.
\end{abstract}

Durante el siglo XviII pierde aún más su carácter estrictamente religioso, llegando a usarse como joya, puesto en el cuello: "dos rosarios para el cuello, con zinco medallas = 18rs." (Colmenar de Oreja, 1798); "un rosa-

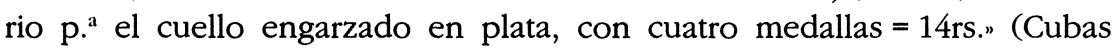
de la Sagra, 1816). Se acentúa más su función ornamental, inseparable del vestido de ceremonia, junto a basquiñas y mantillas de oscura tonalidad ${ }^{24}$. Los rosarios son, después de los pendientes, el elemento más abundante en los inventarios. Los más frecuentes son los estrellados, cuyas características ignoramos; acaso aluda a su estructura, quizá a la forma de sus cuentas, o tal vez a las cruces estrelladas que a veces los remataban:

"tres Rosarios de Jerusalen con sus cruces estrelladas, todos de una misma calidad buenos = 36rs." (Alcorcón, 1764); "dos Rosarios de Jerusalen, el uno con Cruz de plata, y el otro con cruz estrellada $=20$ rs.” (Valdaracete, 1812).

Otros ejemplos de rosarios estrellados:

"dos Rosarios estrellados el uno con seis medallas de Plata de diferentes tamaños $=30$ rs." (Cubas de la Sagra, 1794); "un Rosario estrellado con doce meda-

22 Marqués de Lozoya, Catálogo de la colección de rosarios. Trabajos y materiales del Museo del Pueblo Español (Madrid, s/f).

23 D'Aulnoy, op. cit., pp. 231-232.

21 Véase Amelia Leira SÁnChez, "El traje en el reinado de Carlos III", Moda en sombras (Madrid: M. ${ }^{\circ}$ de Cultura, 1991), pp. 16-20. 


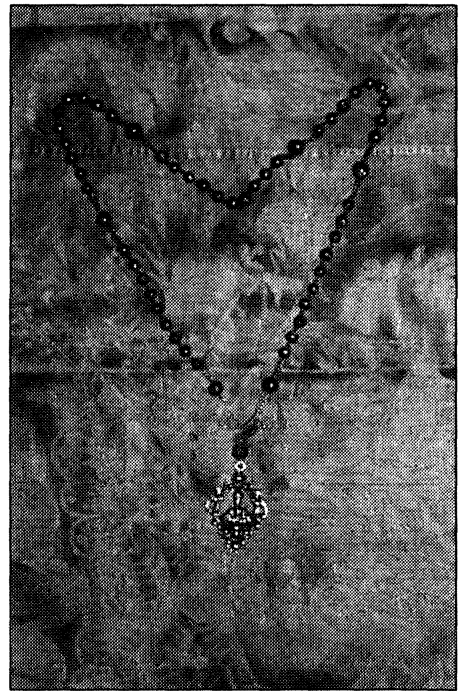

FIG. 8.-Rosario de cuentas azules. Valdaracete.

llas $=30$ rs." (El Álamo, 1799); "un rosario estrellado con diez y siete medallas de Plata $=50$ rs. ( Colmenar de Oreja, 1801); aun Rosario estrellado con ocho medallas de plata y otro lo mismo con tres medallas de plata $=88$ rs.n (Villarejo de Salvanés, 1819).

Numerosos son también los de Jerusalén, normalmente de madera de olivo de la Ciudad Santa; todavía hoy son muy populares y apreciados, aunque sólo se encuentran los de diseño moderno. Se citan estos rosarios en Estremera de Tajo (1769 y 1771), Pozuelo de Alarcón (1776 y 1797), Villamanta (1805), Villarejo de Salvanés (1796), San Lorenzo del Escorial (1808), El Álamo (1790 y 1795), Chinchón (1805), Valdaracete (1812), Carabaña (1792), Vallecas (1846) y Arganda del Rey (1789).

Igualados en la frecuencia de su aparición, los de nácar y los tradicionales de piedras azules; de alguno de estos últimos hemos hallado ejemplos en nuestro trabajo de campo (Fig. 8).

NÁCAR: "un Rosario de nacar con ocho medallas de Plata de diferentes tamaños $=130$ rs." (Cubas de la Sagra, 1794), "un rosario de Nacar con Cruz de Plata y siete medallas de Plata $=60$ rs." (Arganda, 1806); "un Rosario de nacar con cinco medallas pequeñas y un christo de plata $=20$ rs." (Chinchón, 1807); "un rosario de nacar con cuatro medallas grandes, una pequeña, y un Sto. Cristo de plata $=62$ rs. (Vallecas, 1842); etc. AZULES: “...un Rosario q. tengo de piedra azul con sus medallas de plata..." (Pinto, 1788); "un rosario azul con medallas de plata $=30$ rs." (Carabaña, 1792); "un Rosario cuentas de vidrio azul con ocho medallas, y un Christo de plata $=92$ rs." (Navalcarnero, 1800); "Mando [...] mi Hija Legitima un Rosario Azul con engaste de plata y varias medallas de lo mismo.... (Brunete, 1801); "un Rosario sus cuentas azules de piedra con ocho medallas de plata de varios tamaños, $y$ otras cinco pequeñas sueltas $=140 \mathrm{rs}$. . (Humanes de Madrid, 1811).

Destaquemos lo frecuente de los rosarios de nácar en Arganda en todas las épocas consultadas. Son también de gran tradición, los rosarios de cuentas de hueso:

"un rosario con cuentas de hueso blancas, con nueve medallas de plata, y una cruz guarnecida $=64 \mathrm{rs} . "$ (Navalcarnero, 1800), "un Rosario de hueso, engarzado con su borla, y Cruz de Plata = 26rs." (Carabanchel de Arriba, 1803); "un Rosario de Gueso con doze medallas de Plata $=35$ rs." (Chinchón, 1806); "un rosario de hueso, con medallas de Plata $=24 \mathrm{rs} . "$ (Valdeavero, 1834). 
A veces se citan en los inventarios las borlas de colores que solían adornarlos:

"...un Rosario Estrellado engarzado con Cordon de Seda de color de oro con su borla de lo mismo" (Alcorcón, 1765); "un Rosario de Piedra Azul con Borla Azul y encarnada y Sta. de plata $=20 \mathrm{rs}$. ." (Arganda del Rey, 1773); "un Rosario con una Medalla y borla encarnada $=20$ rs.” (Cubas de la Sagra, 1796).

Otros materiales menos frecuentes son el CORAL: aun Rosario de Coral encarnado $=2$ rs." (Majadahonda, 1791); la VENTURINA, a la que se atribuían propiedades protectoras contra ciertas enfermedades: "un Rosario de benturina, engarce de plata, Xrto. de oro, seis medallas de plata sre. doradas, grandes $=600 \mathrm{rs} . "$ (Navalcarnero, 1800); o la MADERA: "un rosario de madera con nuebe medallas pequeñas de plata $=28$ rs." (Barajas de Madrid, 1835).

Como se podrá apreciar por los ejemplos aportados, choca la cantidad de medallas que solían llevar estos rosarios. Isidra Camacho, de Estremera, nos contaba cómo su abuela, de condición modesta, poseía uno de azabache con cuatro o cinco medallitas recortadas en cada uno de los dieces: "dos Rosarios con Sus medallas de Plata cinco el uno y el otro un Cristo y á los Diezes una $=60$ rs." (Villamanta, 1808). Hasta diecisiete de diferentes clases y tamaños se llegan a citar en alguno de los inventariados. Hay que decir que el crucifijo no siempre era pieza imprescindible, como es el caso del conservado en el Museo del Pueblo Español de Madrid, de alambre y con seis medallas, procedente de San Martín de Valdeiglesias (Fig. 9).

\section{PIEZAS PARA LA CABEZA}

Para componer el peinado, la mujer utilizaba diversas piezas como agujas, pasadores, horquillas y peines, que a veces se confeccionaban con materiales que pueden encuadrarse dentro de la joyería. No se encuentran muchas citas sobre estos elementos en los inventarios, y poco sabemos de su uso en la provincia de Madrid (contrariamente a lo que ocurre en

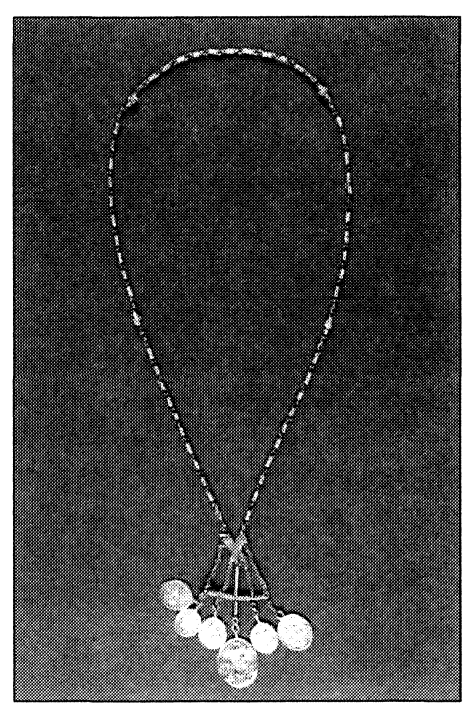

FIG. 9.-Rosario. San Martín de Valdeiglesias. Col. Museo del Pueblo Español de Madrid (núm. inv. 7008). 
otras regiones donde eran parte inexcusable del aderezo). Aparecen algunas agujas o alfileres para el peinado, y en algunos pueblos, como en Arganda, todas las mujeres poseían una de plata: "una Abuja, Rascamoño y Alfiler $=40$ rs." (Arganda del Rey, 1773); "dos Abujas de Plata $=40$ rs." (Arganda del Rey, 1806); "una Abuja de plata $=10$ rs." (Arganda del Rey, 1808); "una aguja de plata $=20$ rs." (Arganda del Rey, 1810); etc. Parecen hacer distinción entre la aguja, el rascamoño y el alfiler, que aparecen independientes o asociados en otros pueblos: "un rascamoño y Alfiler de plata $=10$ rs." (Valdemorillo, 1772); "un Rasca Moños de plata y dos alfileres también de plata $=16$ rs." (Pozuelo de Alarcón, 1781). Otras citas, más tardías, se refieren a alfileres de mantilla: "dos Alfileres de Mantilla $=24 \mathrm{rs}$." (Santorcaz, 1834), "cuatro alfileres para la mantilla $=16 \mathrm{rs}$." (San Lorenzo del Escorial, 1840). El resto de los ejemplos de alfileres, que aparecen por toda la provincia, y que suelen ser de oro, similor o plata, son poco concisos, y posiblemente fueran también alfileres para sujetar el pañuelo del cuello.

Entre los peines, se citan gran cantidad de los de concha, en fechas más modernas y que podemos considerar más dentro de la moda urbana. Parece que en algunos lugares, como es el caso de Carabanchel, era corriente llevar peines de plata en la cabeza, pues por las abundantes citas podemos deducir que casi todas las mujeres poseían uno. Las informantes denominan escarpidores o batidores al utensilio con que se peinan, reservando la voz peine para las piezas de adorno de la cabeza ${ }^{25}$. En Villarejo de Salvanés guardan un vago recuerdo de painas de marfil que se llevaban sobre el moño. Más vivo está el de las agujas de bueso en Robledondo; hacían las veces de pasador para el rodete y alguna de ellas hemos llegado a ver. Son de forma ahusada, de unos $12 \mathrm{~cm}$. de longitud y llevan grabados sencillos motivos a punta de navaja. Solían ser regalo de los mozos a sus enamoradas (Fig. 10). Persiste también el recuerdo del uso de grandes horquillas doradas en los rizos que

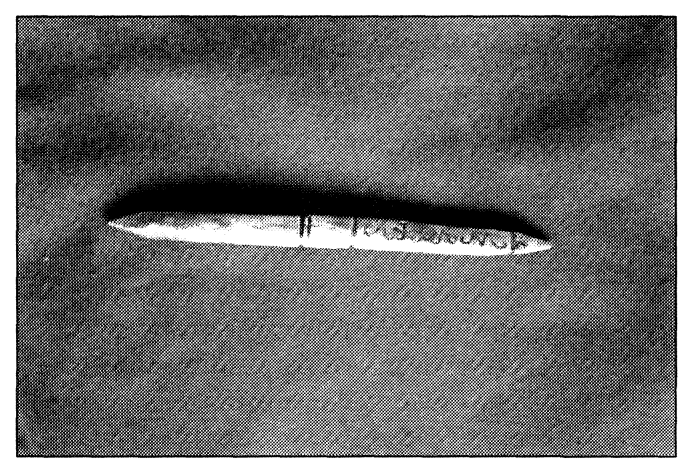

FIG. 10.-Aguja de hueso. Robledondo. Col. Jose Manuel Fraile Gil. $12 \mathrm{~cm}$.

25 Más información sobre el peinado en Madrid en José Manuel FraILE GIL, «Notas tradicionales sobre el pelo y su cuidado en Madrid y la zona centro", Revista de Folklore, núm. 73, II (año VII), (1987) pp. 3-5. 
acompañaban al moño de picaporte —en el peinado a tres bandas- en Colmenar de Oreja. Algunos ejemplos más de agujas y peines:

"una Aguja de plata para el pelo = 25rs." (Majadahonda, 1791); "tres Alfileres para el pelo $=15$ rs." (Colmenar de Oreja, 1798); "dos abujas para el pelo de metal 1r." (Colmenar de Oreja, 1798); "un Peine de acero 26rs." (Arganda del Rey. 1809); "un peine de Azero = 12rs." (Villamanta, 1810); etc.

\section{DIJEROS INFANTILES Y OTROS AMULETOS}

En su viaje a Madrid, la Condesa d'Aulnoy se detuvo en una posada de San Agustín de Guadalix con objeto de descansar y preparar mejor su entrada en la Corte. Allí recibió la visita de varios lugareños deseosos de ver de cerca a tan "exótica" huésped:

Entre las mujeres ha venido una especie de burguesa bastante bonita; llevaba a su hijo en brazos; era de una delgadez horrible; llevaba más de cien manecillas, unas de azabache, otras de barro tallado, atadas a su cuello y colgando de él por todas partes. He preguntado a su madre qué significaba aquello; me ha contestado que eso servía contra el mal de ojo ${ }^{26}$.

A primera vista pudiera parecer una de las características exageraciones que salpican el relato de la ilustre dama, si no fuera por la cantidad de retratos conservados de niños de la Corte en esa época, y aún de la familia real, que se nos presentan acorazados por multitud de dijes y amuletos. Es curiosa la frecuencia con que aparecen estos dijeros en los inventarios, y aún sorprende más si tenemos en cuenta su abundancia en pueblos del entorno de la capital. Algunos son tan completos que no nos resistimos a transcribirlos íntegros aquí:

"un atado de diges de plata q.e se compone de cinco medallas grandes de varias Ymagenes, una del pilar de Zaragoza macizo, tres relicarios, un tejo [sic por tejón], una mano de christal engastada en plata con su cadenilla y un chupador con el mismo engaste $=170$ rs.. (Pozuelo de Alarcón, 1803); «un Lazo p. ${ }^{a}$ Niño, que contiene unos Volsillos de Seda, un Chupador de Cristal con cerco y Cadena de Plata, Una Piedra figura de corazon, y una mano de cristal, con Cercos de Plata; tres medallas de lo mismo, tres relicarios con igual cerco, y un Colmillo de Plata $=70$ rs.", "Otro Lazo de Zinta de Color de Rosa y á él unidos unos volsillos, Evanjelios, Una Bota, y una regla, forrado en tisu; una Campanilla, y una Cestita con Cascabeles todo de Plata, un Chupador de Cristal Pintado, una punta de Cuerno, y una mano de tejon con sus Cercos y Cadena de Plata; Una nuestra Señora del Pilar, afeligranada con cinco Piedras encarnadas; otra medalla del Pilar; Un relicario figura de corazon, con Un

26 D'AulNoY, op. cit., p.192. 
Christo y una Virgen todo de plata; otro relicario mas Pequeño con Cerco de Plata por un lado Jesus Nazareno, y por otra nuestra Señora de la Soledad; otro algo mayor con igual cerco, por un lado San Juan, y por otro nuestra Señora; Otro relicario de Sn. Antonio Embutido en plata, una mano de Coral, con engarze de Plata, y tres medallas de lo mismo, las dos de Guadalupe y la otra de grazia $=438$ rs." (Villamanta, 1805); "unos dijes que se componen de un relicario, un Cornatito un Corazon y una birjen Engarzado en Plata, y una mano de tejon con Bolsillos $=26$ rs." (Villamanta, 1809); “uno dijes que se componen de bolsillos y Ebangelios bordado de lantejuela de oro con tres medallas de N. ${ }^{a}$ Sra. del Sagrario, otras dos de Crucifijos, un relicario con la efijie de N. ${ }^{2}$ Sra. de la Soledad, un corazon de plata con un Santo Cristo, Tres medallas pequeñas, un Cascabelero, una Campanilla con su cadena todas estas piezas de Plata, y un chupador de vidrio, con su cadena de plata $=230$ rs." (Humanes de Madrid, 1811), "una Regla forrada con Grase [sic] de Plata un Colmillo engarzado en plata y su Cadena de lo mismo, Un Coral tambien engarzado en lo mismo, un Crucifijo de Plata afeligranado, y una Medalla de Nra. Señora tambien de plata $=38$ rs.." (Villarejo de Salvanés, 1817).

Creemos que estos ejemplos son suficientemente expresivos por sí mismos. Digamos también que higas de coral, azabache o cristal aparecen en Cubas de la Sagra (1798), Chinchón (1807 y 1840), Estremera de Tajo (1803), Pozuelo de Alarcón (1750 y 1799), Villarejo de Salvanés (1818), Campo Real (1839), Vallecas (1846), Loeches (1773) y Valdaracete (1817). El recuerdo de estas higas está vivo en algunos pueblos del sureste provincial. En Chinchón eran de hueso con engarce de metal, y en Estremera, donde las llamaban hitas, solían ser negras - probablemente de azabache- también engarzadas en plata u otro metal.

Son muchas las referencias a campanillas de plata y cascabeleros que ahuyentaban el mal con su sonido, además de servir como sonajero o juguete para los niños. Unas y otros se citan abundantemente en casi todos los pueblos.

De los diferentes amuletos de origen animal, tenemos muestras de cuernos, colmillos y patas de tejón, además de los ya mencionados en los dijeros; se nombran cuernos en Cubas de la Sagra (1798), Brunete (1801) y Villamanta (1805 y 1810); y patas de tejón en Pozuelo de Alarcón (1750) y Valdaracete (1817). Son escasos los de forma vegetal: en algún inventario hemos encontrado "una piña engarzada en plata" entre los dijes de niño (Estremera de Tajo, 1803).

Todos estos amuletos solían ir acompañados de un sinnúmero de medallas y relicarios de diferentes santos. En El Berrueco nos explicaron cómo ataban en el empezar y en la punta del fajero unas medallas pequeñas que sobresalían por el borde del mismo al envolver las mantillas. Las medallas de Santa Elena —en realidad monedas bizantinas engarzadas en algún metal- tampoco están ausentes en los protocolos. En Villarejo nos contaban que las colocaban a los niños entre las envueltas junto a 
una corteza de pan y unos evangelios obra de las monjas de Chinchón: "un Coral higa, y Santa Elena, con engarce de plata $=20$ rs." (Villarejo de Salvanés, 1818); "una medalla de Sta. Elena engarzada en plata" (Vallecas, 1846); etc.

Hay pocos amuletos de los que podamos asegurar que fueran usados por los adultos, pues nada de esto queda en el recuerdo de las gentes. Se citan, eso sí, las famosas cuentas de leche, que suspendían las mujeres junto al pecho con objeto de facilitar la lactancia, además de algunas cruces y medallas con diferentes advocaciones que tenían poder protector contra males concretos:

"...quatro quentas de leche..." (Alcorcón, 1764); “Mando á mi nieta Antonia Mtñ. las Cuentas de Leche p. ${ }^{a}$ que pida á Dios por mi Alman (Manjirón, 1800); "una cuenta de leche $=6$ rs." (Valdetorres de Jarama, 1837); "dos cuentas de leche $=10$ rs." (Vallecas, 1846) ${ }^{27}$.

Hemos dejado para otra ocasión los elementos más íntimamente relacionados con la ropa, como botones y hebillas, así como las joyas de las manos: sortijas y anillos; piezas todas estas que se citan también con frecuencia en los inventarios. Sirva pues este trabajo como primer peldaño y orientación para estudios de otras zonas que puedan ir conformando poco a poco el todavía incompleto mapa de la indumentaria y el adorno personal, tradicionales de nuestro país.

\section{MARCOS LEÓN FERNÁNDEZ}

El presente artículo pretende, a través de un primer muestreo, ofrecer una visión general aproximada de la joyería tradicional en la provincia de Madrid -especialmente aquellas piezas relacionadas con la indumentaria-, a partir de los datos obtenidos de los inventarios de los siglos XviII y XIX y del trabajo de campo. Las piezas se ordenan según su uso, forma y denominación, tratando de hacer coincidir estos tres aspectos cuando ello es posible.

This article deals with peasant jewellery from the province of Madrid (Spain) in the eighteenth and nineteenth centuries, especially those pieces closely related to the regional costume. They have been classified according to "use" "form" and "name". Examples from inventories of the period are provided. The study is based on fieldwork and inventories of the time and is viewed as a first approach or general outlook into the subject.

27 Sobre usos y propiedades de amuletos, véase Concepción AlarCón ROMÁN, Catálogo de amuletos del Museo del Pueblo Español (Madrid: M.º de Cultura, 1987). 